\title{
Corrigendum to "Assessment of tsunami hazards for the Central American Pacific coast from southern Mexico to northern Peru" published in Nat. Hazards Earth Syst. Sci., 14, 1889-1903, 2014
}

\author{
B. Brizuela ${ }^{1, *}$, A. Armigliato ${ }^{2}$, and S. Tinti ${ }^{2}$ \\ ${ }^{1}$ Istituto Nazionale di Geofisica e Vulcanologia, Rome, Italy \\ ${ }^{2}$ Dipartimento di Fisica e Astronomia, Università di Bologna, Bologna, Italy \\ * formerly at: Dipartimento di Fisica e Astronomia, Università di Bologna, Bologna, Italy
}

Correspondence to: B. Brizuela (beatriz.brizuela@ingv.it)

In the recently published version of the paper entitled "Assessment of tsunami hazards for the Central American Pacific coast from southern Mexico to northern Peru" by B. Brizuela, A. Armigliato and S. Tinti, some errors occurred, which we list here below:

- p. 1893, first column, 13 rows from the bottom: "(see Fig. 4)" should read as "(see Fig. 3)"

- p. 1894, Eq. (2) should read as follows:

$$
\log N=a+\log \left(\frac{e^{-\beta M}-e^{-\beta M_{\max }}}{e^{-\beta M_{\min }}-e^{-\beta M_{\max }}}\right)
$$

- p. 1894, Eq. (3) should read as follows:

$$
\beta=\frac{b}{\log (e)}
$$

- p. 1899: Figs. 9 and 10 must be replaced by the figures shown on the right-hand side

- p. 1901, first column: "hazards" should read as "hazard"

- p. 1901, second column: the correct reference to CERESIS is the following: CERESIS (Centro Regional de Sismología para América del Sur), available at: http://www.ceresis.org/portal/catal_hipo.php, last access: April, 2009.
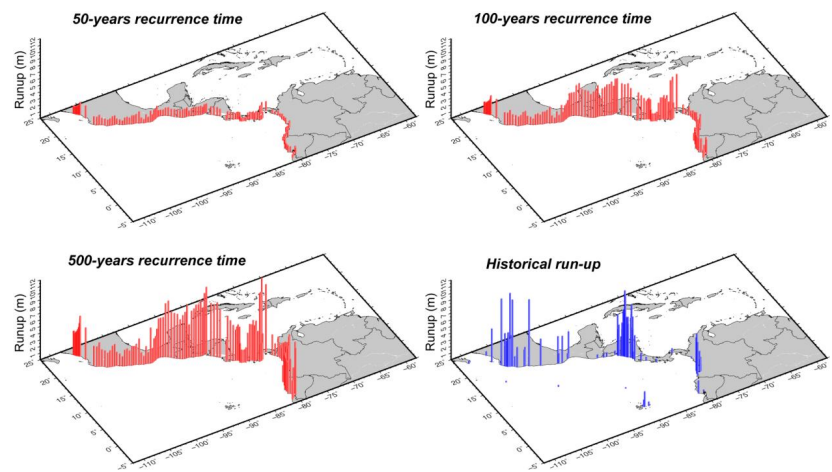

Figure 9. Maximum expected run-up height distribution for different return periods and observed historical run-up heights.

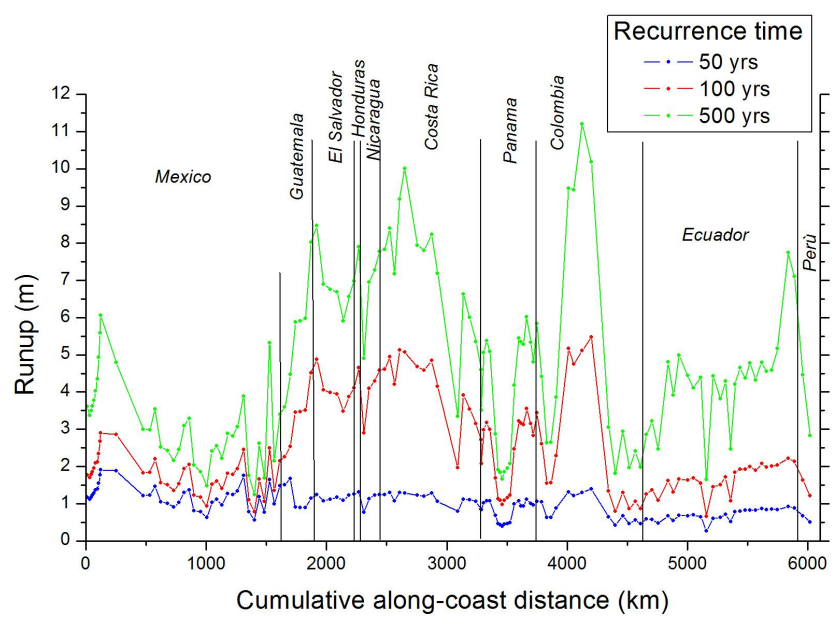

Figure 10. Maximum expected run-up distribution vs. distance along the coast. 